\title{
DECREASE OF REPEATED CONTAMINATION OF PACKED DELICIOUS MEAT PRODUCTS
}

\author{
Lydmila Vinnikova ${ }^{1}$ \\ vinnikova.kaf@gmail.com \\ Olha Synytsia ${ }^{1}$ \\ olia4ka2403@gmail.com \\ Halyna Shlapak ${ }^{1}$ \\ shlapak.galya@mail.ru \\ Nadiia Azarova ${ }^{1}$ \\ azarova.nad.53@gmail.com \\ Oleg Glushkov \\ Odessa Technical College of Gas and Oil Industry \\ 46-a Levitana str., Odessa, Ukraine, 65088 \\ olegglushkov777@gmail.com \\ ${ }^{1}$ Department of meat, fish and seafood technology \\ Odessa National Academy of Food Technologies \\ 112 Kanatna str., Odessa, Ukraine, 65039
}

\begin{abstract}
The study considers a problem of repeated contamination of delicious products, ready for consumption. The aim of the work is to study the repeated thermal pro-cessing of a ready vacuum-packed whole-muscular meat product for inhibiting a surface microbiota.

Today it is urgent for the meat industry, because it influences safety and quality, and also limits a storage term of a product.

After bringing a meat product to culinary readiness by thermal processing, it has an unessential amount of microbiota. Microorganisms, including pathogenic and conventionally pathogenic ones, fall on a product after its cooking at cutting, preparation to package and at the package stage itself. Microbiological contamination of a ready meat product results in fast spoilage and is a serious problem for producers, because the microbiota growth shortens its storage life. In its turn, it results in a refuse of a consumer to buy this product and great economic losses for producers.

The study is directed on a possibility of solving a problem of contamination of a whole-muscular delicious meat product. The solution is in package of a ready product under vacuum and short-term heating at a high temperature.

The work is devoted to the complex study of an influence of repeated pasteurization on safety and quality of a product. There was studied an influence of the repeated thermal processing (post-pasteurization) on microbiological, physical-chemical and also organoleptic parameters of a delicious meat product.

The special attention is paid to an influence of post-pasteurization regimes on a microbiological condition of studied samples. Studies of a total amount of microbiota and also the presence of sanitary-representative microorganisms were conducted.

It has been proven, that the use of post-pasteurization essentially inhibits a number of microorganisms, and also doesn't influence physical-chemical parameters outlook of a product and organoleptic characteristics.

Based on studying an influence of post-pasteurization, it has been established, that inhibition of a microbiota essentially influences safety and prolongs the storage term of a product.
\end{abstract}

Keywords: post-pasteurization, delicious meat products, microbiota, thermal processing, vacuum package.

DOI: $10.21303 / 2504-5695.2019 .00996$

\section{Itroduction}

Meat and meat products contain valuable nutritive substances for the human growth and heath and are an important part of a ration. Because of a high food value, meat products are ones 
of most demanded for consumption. Unfortunately, meat products are fast-spoiling and subjected to microbiological contamination. Semination by microorganisms results in serious problems with safety and quality of a product, and also in economic losses for a producer [1-3].

A question of microbiological safety is important for the meat industry, because spoilage of meat products takes place mainly because of microorganisms [4]. Meat and meat products contain plenty of proteins, enough quantity of water and main nutritive substances with $\mathrm{pH}$, favorable for the microbiota growth $[5,6]$. As a result of the life activity of microorganisms, proteins and lipids in a meat product are subjected to denaturation, unfavorable changes of microbiological characteristics, worsening of taste characteristics takes place [2].

A microbiota that causes spoilage of meat and meat products is represented by such mechanisms as Pseudomonas, Acinetobacter, Brochothrixthermosphacta, Moraxella, Enterobacter, Lactobacillus, Leuconostoc and Proteus. As a rule, microorganisms that cause a fact that a product is spoiled, doesn't cause damage to a human, but at their great number can result in disorders of the work of the gastrointestinal tract [7].

For improving a microbiological condition and prolonging a storage term of meat products, it is possible to affect a product after cooking by inhibiting a surface microbiota that fell on a product after its cross contamination [8-11].

One of ways of improving a microbiolgical condition of a meat product and prolonging storage terms may be the use of repeated thermal processing of a vacuum-packed product [12-14].

The aim of this work is to estimate a possibility of inhibiting a surface microbiota of a ready delicious meat product, packed in vacuum by pasteurization, without changing organoleptc characteristics.

The studying procedure is based on the following generalized knowledge:

- an influence of thermal processing on microorganisms and also quality, structural-mechanical and organoleptic parameters of a product $[2,14,15]$;

- an influence of vacuum package on the microbiota life activity in a meat product $[16,17]$;

- thermostable properties of packing films.

\section{Materials and methods}

Samples of smoked-boiled meat "Balyk vintage" of the highest sort were used in the study. All samples were produced at PE "GARMASH" (Ukraine, Odessa region).

The samples were cooked of $100 \%$ meat of spine-lumbar muscles of pork semi-carcass with adding culinary salt (2.5\% of the meat mass) and pickle preparation (density $1,087 \mathrm{~g} / \mathrm{cm}^{3}$, consisting sodium nitrites $0,05 \%$ and sugar $0.5 \%$ ).

All raw and ready materials, used in the study, corresponded to actual standards of Ukraine in the aspect of quality and safety.

\section{1. Experiments}

After bringing the product to culinary readiness, it was cooled to temperature $6-8{ }^{\circ} \mathrm{C}$, cut in pieces of $100 \mathrm{~g}$ and packed under vacuum in multi-layer polymeric films with width 95 microns, produced by «Orved» (Italy). Package was realized on the vacuum-packing machine, produced by «Cryovac» (Switzerland).

The experimental samples, packed in vacuum, were subjected to post-pasteurization in the electric digester SVC-14, produced by Sammic S. L. (Spain) Fig. 1. After post-pasteurization, the samples were cooled to temperature $6-8{ }^{\circ} \mathrm{C}$ and kept in the refrigerator Liebherr (Germany) at temperature $4{ }^{\circ} \mathrm{C}$ during the whole term. Together with the experimental samples, subjected to post-pasteurization, balyk samples in a vacuum package without post-pasteurization (control samples) were kept under equal conditions in the refrigerator. All samples were kept in the refrigerator during 35 days.

The experimental studies were three- and fivefold repeated. The obtained results were presented in units of the international system CI.

The microbiological studies were conducted in the laboratory of the department of "Biochemistry, microbiology and physiology of nutrition" of the Odessa national academy of food technologies (Ukraine). Microbiological parameters characterize the product safety and also prognosticate and establish its storage term. 


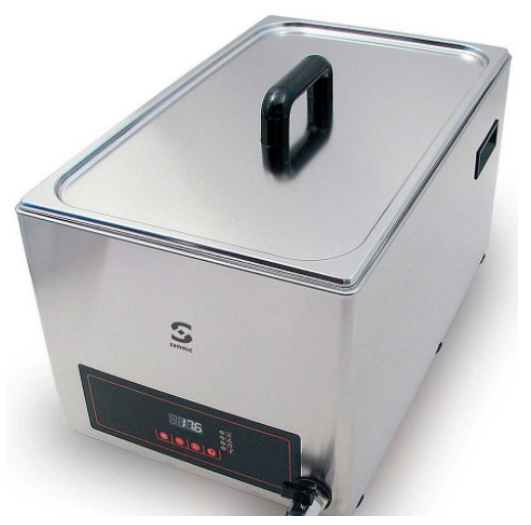

Fig. 1. Digester SVC-14

The study was prepared and a batch of the product was taken by sterile instruments under conditions, excluding contamination of a product by microorganisms from the environment. Samples were selected, according to SS 26669-85. The sample batch of $10 \pm 0.05$ was placed in a sterile bottle with $90 \mathrm{~cm}^{3}$ of a sterile physiological solution and mixed by round movements during 10-15 minutes. A supernatant liquid is a washout of microorganisms from the product that is in dilution 1:10.

After 14 days of storage the inoculation from dilutions was realized. For preparing dilutions of test samples, $1 \mathrm{ml}$ of the supernatant liquid of the preliminarily prepared sample was taken by a sterile pipette and transferred to a sterile test tube, containing $9 \mathrm{ml}$ of the sterile physiological solution. The content of the test tube was accurately mixed. As a result dilutions 1:100 were obtained.

At 35 and 42 day of storage the inoculation from dilution1:1000 was realized. For such dilutions of test samples, $1 \mathrm{ml}$ of the suspension was taken by a sterile pipette from the test tube with dilution 1:100 and transferred to another test tube, containing $9 \mathrm{ml}$ of the sterile physiological solution and mixed accurately.

A number of mesophilic aerobic and facultative-anaerobic microorganisms was determined, according to SS 8446:2015 Food products. Methods of determination of mesophilic aerobic and facultative-anaerobic microorganisms. This method is based on the ability of microorganisms to multiply on a dense nutritive agar at temperature $30 \pm 1^{\circ} \mathrm{C}$ during 72 hours.

The inoculation of test samples was realized by taking $1 \mathrm{ml}$ of the suspension of the correspondent solution and introducing it in a Perti dish. After that the heated nutritive medium meat-peptonic agar (MPA) with temperature $45 \pm 1{ }^{\circ} \mathrm{C}$ in amount $12 \ldots 15 \mathrm{ml}$ was evenly distributed along the whole Petri dish surface by round movements. After congelation of the nutritive medium, Petri dishes were directed in the thermostat for incubation.

Bacteria of the colon bacillus group (BCBG) were determined, using Kessler medium, according to SS 998-81, because BCBG ferment lactose and as a result acid and gas form during 24 hours at temperature $37 \pm 1^{\circ} \mathrm{C}$.

For determining sulfite-reducing clostridia, the method of inoculating $1 \mathrm{~cm}^{3}$ of the supernatant liquid of the product in the sulfite cyclosulfuric medium (SCS) and Wilson-Blair one, according to SS 998-81, was used. The inoculation was kept in the thermostat at temperature $37 \pm 1^{\circ} \mathrm{C}$ during 18-24 hours.

Pathogenic microorganisms, including Salmonellaspp., were determined by inoculation on the selective medium, and their serological and enzymatic properties were established, according to SSU ISO 6579 Microbiology of food products and fodders for animals.

Staphylococcusaureus were determined, according to SS 10444.2-94. The batch of the studied product was $25 \mathrm{~g}$. The inoculation was realized in the liquid selective (with preliminary enrichment) and on the dense selective-diagnostic mediums. The inoculations were incubated at temperature $36 \pm 1{ }^{\circ} \mathrm{C}$ during $24-48$ hours. At that the preliminary calculation was conducted in a day, and the final one - after 48 hours.

The physical-chemical and organoleptic studies were conducted at the department of "Technology of meat, fish and seafood" of the Odessa national academy of food technologies 
(Ukraine). During the study a concentration of nitrogen ions $(\mathrm{pH})$ was determined. $\mathrm{pH}$ index was determined by the potentiometric method, using H-meter Testo 205 (Germany) Fig. 2. The methodology provides taking of a sample of comminuted meat with mass $10 \mathrm{~g}$ and mixing during $25 \mathrm{~min}$ in $100 \mathrm{ml}$ of distilled water. After that, the obtained extract was filtered and $\mathrm{pH}$ of the filtrate was determined [18].

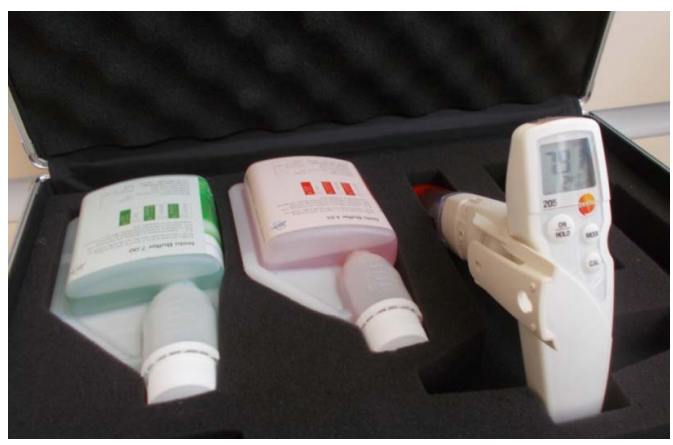

Fig. 2. pH-meter Testo 205

The amount of moisture was determined in the experimental and control samples. The mass share of moisture was determined by the accelerated methodology [19], by drying at temperature $150{ }^{\circ} \mathrm{C}$ during 1 hour $5 \mathrm{~g}$ of the batch of dried meat, rubbed with $6 \ldots 7 \mathrm{~g}$ f sand and preliminarily weighted. Drying was conducted in the drying chamber 2B1-51 (Ukraine). The dried box with the product was placed in the exsiccator. After complete cooling, it was weighted on scales and the mass share of moisture $\left(X_{m}\right)$ was calculated by formula (1):

$$
X_{m}=\frac{(a-b)}{m} \cdot 100 \%
$$

where $a$ and $b$ - mass of the box with the batch before and after drying, respectively, g; $m$ - batch mass, $g$.

For checking freshness, quality and safety, presence or absence of changes, the organoleptic studies were conducted after post-pasteurization. The organoleptic studying method is based on analyzing perceptions of the sense organs: sight, hearing, smell, touch and taste. The samples were assessed for establishing correspondence of organoleptic quality parameters to requirements of TC U 15.1-33381354-007:2012. The organoleptic studies were conducted using a five-point scale of assessment. Based on the obtained points, the total point of each sample was calculated. The study was conducted by 6 tasters. During the whole storage term, there were determined such parameters as outlook, consistence, cut look, smell and taste [18].

\section{Results}

During the study there were determined main microbiological, physical-chemical and organoleptic parameters of the experimental and control samples of whole-muscular delicious meat products.

Meat products of $100 \mathrm{~g}$ in a vacuum package were heated at temperature $90{ }^{\circ} \mathrm{C}$ during $1 \mathrm{~min}$ (sample 1), 2 min (sample 2) and 3 min (sample 3).

Table 1 presents the results of the total number of microorganisms (MAFAnM) in the control sample, and also the number of microorganisms in the experimental samples at 1 day of storage.

Table 1

Index of the total number of mesohilic aerobic and facultative-anaerobic microorganisms at 1 day of storage

\begin{tabular}{ccccc}
\hline Parameter & Control & Sample 1 & Sample 2 & Sample 3 \\
\hline MAFAnM, CFU in 1 g & $2.0 \cdot 10^{2}$ & $1.4 \cdot 10^{2}$ & $9.5 \cdot 10^{1}$ & $<10$
\end{tabular}


Table 1 testifies that the use of pasteurization of the ready delicious meat product, packed in vacuum, essentially inhibits the microbiota.

There were studied the sanitary-representative microorganisms, such as sulfite-reducing clostridia, Salmonella, St. aureus, and also bacteria of the colon bacillus group. The results of these studied demonstrated that no listed microorganisms were found in the product.

The microbiological studies were conducted during the whole storage term in each 7 days. During the storage process there was observed the intensive growth of microorganisms in the control sample, and at 28 day of storage the norm of MAFAnM was essentially exceeded [18].

The growth of microorganisms in experimental samples 1 and 2 was less intensive, but at 28 day it exceeded the norm of MAFAnM along with the control. During the storage process sample 3 had the inessential growth of the microbiota and even at 35 day didn't exceed the normative index of total semination.

The sanitary-representative microorganisms were not found during all 35 days of storage in the control and experimental samples.

The effect of thermal processing has the influence on all components of the meat product and can change its outlook and structure [15]. The aim of our work was to diminish the number of microorganisms without changing organoleptic indices of the product. At the same time the storage term of the product is determined by not only microbiological parameters, but also by organoleptic characteristics. The sour-milk bacteria, such as: Lactobacillus, Carnobacterium and Leuconostoc mainly dominate in the product, packed under vacuum. The presented bacteria produce acids: lactic, acetic and formic ones and influence the product taste [20].

The studies of the organoleptic parameters testify to the fact that post-pasteurization doesn't influence the outlook of the product and doesn't cause changes of its organoleptic parameters.

During the process of storage the control sample at 28 day had spoilage signs, namely the sour smell. Control sample 3 didn't have any outlook changes and also taste and smell ones, even at 35 day of storage. Fig. 3 presents photos of the samples of whole-muscular delicious meat products at 35 day of storage.

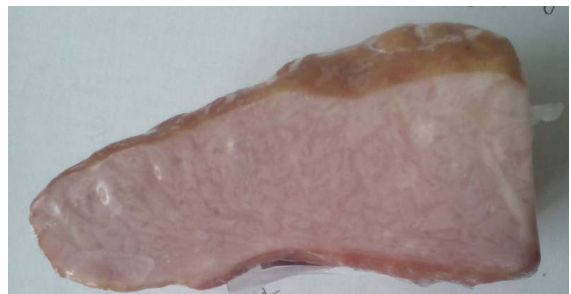

$a$

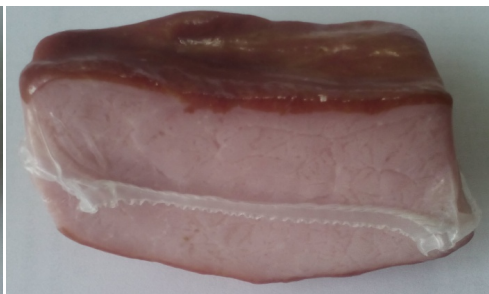

$b$

Fig. 3. Samples of whole-muscular delicious meat products: $a$ - control; $b$ - Sample 3 at 35 day of storage

The studies of $\mathrm{pH}$ and mass share of moisture demonstrated that post-pasteurization has no influence on the concentration of nitrogen ions and doesn't cause free moisture release from the product.

\section{Conclusions}

1. Inhibition of the microbiota of the ready whole-muscular delicious meat product, packed in vacuum, has been proven.

2. It has been established, that post-pasteurization essentially improves the microbiological condition of the product.

3. Temperature-temporal regimes of repeated pasteurization don't cause changes of the product outlook.

4. It has been proven, that the product, subjected to post-pasteurization, has more storage term.

5. The effectiveness of repeated pasteurization at temperature less $90{ }^{\circ} \mathrm{C}$ was not verified during the study. Further studies will be directed on searching for optimal post-pasteurization regimes for prolonging storage terms of whole-muscular delicious meat products. 


\section{References}

[1] Lorenzo, J. M., Munekata, P. E., Dominguez, R., Pateiro, M., Saraiva, J. A., Franco, D. (2018). Main Groups of Microorganisms of Relevance for Food Safety and Stability. Innovative Technologies for Food Preservation, 53-107. doi: https://doi.org/10.1016/ b978-0-12-811031-7.00003-0

[2] Vinnikova, L. G. (2017). Tekhnologiya miasnykh produktov. Teoreticheskie osnovy i prakticheskie rekomendatsiyi. Kyiv: Osvita, 364.

[3] Woraprayote, W., Malila, Y., Sorapukdee, S., Swetwiwathana, A., Benjakul, S., Visessanguan, W. (2016). Bacteriocins from lactic acid bacteria and their applications in meat and meat products. Meat Science, 120, 118-132. doi: https://doi.org/10.1016/ j.meatsci.2016.04.004

[4] Hui, Y. H. (Ed.). (2012). Handbook of meat and meat processing.CRC press.

[5] Barbin, D. F., ElMasry, G., Sun, D.-W., Allen, P. (2013). Non-destructive determination of chemical composition in intact and minced pork using near-infrared hyperspectral imaging. Food Chemistry, 138 (2-3), 1162-1171. doi: https://doi.org/10.1016/ j.foodchem.2012.11.120

[6] Dave, D., Ghaly, A. E. (2011). Meat spoilage mechanisms and preservation techniques: a critical review. American Journal of Agricultural and Biological Sciences, 6 (4), 486-510. doi: https://doi.org/10.3844/ajabssp.2011.486.510

[7] Jayasena, D. D., Jo, C. (2013). Essential oils as potential antimicrobial agents in meat and meat products: A review. Trends in Food Science \& Technology, 34 (2), 96-108. doi: https://doi.org/10.1016/j.tifs.2013.09.002

[8] Houben, J. H., Eckenhausen, F. (2006). Surface Pasteurization of Vacuum-Sealed Precooked Ready-to-Eat Meat Products. Journal of Food Protection, 69 (2), 459-468. doi: https://doi.org/10.4315/0362-028x-69.2.459

[9] Fang, Z., Zhao, Y., Warner, R. D., Johnson, S. K. (2017). Active and intelligent packaging in meat industry. Trends in Food Science \& Technology, 61, 60-71. doi: https://doi.org/10.1016/j.tifs.2017.01.002

[10] Chen, J., Brody, A. L. (2013). Use of active packaging structures to control the microbial quality of a ready-to-eat meat product. Food Control, 30 (1), 306-310. doi: https://doi.org/10.1016/j.foodcont.2012.07.002

[11] Luning, P. A., Jacxsens, L., Rovira, J., Osés, S. M., Uyttendaele, M., Marcelis, W. J. (2011). A concurrent diagnosis of microbiological food safety output and food safety management system performance: Cases from meat processing industries. Food Control, 22 (3-4), 555-565. doi: https://doi.org/10.1016/j.foodcont.2010.10.003

[12] Pérez-Rodríguez, F., Zamorano, A. R., Posada-Izquierdo, G. D., García-Gimeno, R. M. (2013). Study of the effect of post-packaging pasteurization and argon modified atmosphere packaging on the sensory quality and growth of endogenous microflora of a sliced cooked meat product. Food Science and Technology International, 20 (1), 3-12. doi: https://doi.org/ $10.1177 / 1082013212469613$

[13] Selby, T. L., Berzins, A., Gerrard, D. E., Corvalan, C. M., Grant, A. L., Linton, R. H. (2006). Microbial heat resistance of Listeria monocytogenes and the impact on ready-to-eat meat quality after post-package pasteurization. Meat Science, 74 (3), 425-434. doi: https://doi.org/10.1016/j.meatsci.2006.02.018

[14] Smelt, J. P. P. M., Brul, S. (2014). Thermal Inactivation of Microorganisms. Critical Reviews in Food Science and Nutrition, 54 (10), 1371-1385. doi: https://doi.org/10.1080/10408398.2011.637645

[15] Vinnikova, L., Synytsia, O., Kyshenia, A. (2019). The problems of meat products thermal treatment. Food Science and Technology, 13 (2). doi: https://doi.org/10.15673/fst.v13i2.1386

[16] Lee, K. T. (2010). Quality and safety aspects of meat products as affected by various physical manipulations of packaging materials. Meat Science, 86 (1), 138-150. doi: https://doi.org/10.1016/j.meatsci.2010.04.035

[17] Cachaldora, A., García, G., Lorenzo, J. M., García-Fontán, M. C. (2013). Effect of modified atmosphere and vacuum packaging on some quality characteristics and the shelf-life of "morcilla", a typical cooked blood sausage. Meat Science, 93 (2), $220-225$. doi: https://doi.org/10.1016/j.meatsci.2012.08.028

[18] Antipova, L. V. (2001). Metody issledovaniya myasa i myasnykh produktov. Moscow: Kolos, 376.

[19] Zhuravskaya, N. K., Alexina, L. T., Otryashenkova, L. M. (1985). Issledovanie i kontrol' kachestva myasa i myasoproduktov. Moscow: Agropromizdat, 296.

[20] Pexara, E. S., Metaxopoulos, J., Drosinos, E. H. (2002). Evaluation of shelf life of cured, cooked, sliced turkey fillets and cooked pork sausages - "piroski" - stored under vacuum and modified atmospheres at +4 and $+10{ }^{\circ} \mathrm{C}$. Meat Science, 62 (1), 33-43. doi: https://doi.org/10.1016/s0309-1740(01)00224-8

Received date 23.07.2019

Accepted date 27.08.2019

Published date 17.09.2019
(C) The Author(s) 2019

This is an open access article under the CC BY license (http://creativecommons.org/licenses/by/4.0). 